\title{
Five Innovation Inspirations from Indian Automobile Market
}

\author{
Maruti Vitthal Khaire ${ }^{1}$, Raghuvir Singh ${ }^{2}$ \\ $\left({ }^{l}\right.$ National Engineering Industries Ltd. \& ${ }^{1,2}$ TAPMI School of Business, Manipal University, Jaipur, India)
}

\begin{abstract}
The present research is study of Indian automobile industry's change triggers and inspirations can be drawn from market for innovations. Research revealed that there are five major inspirations which can be drawn for innovation from Indian automobile industry. This research termed these five main inspirations as five A's of market inspiration for innovations. Affordability, Accessibility, Addressing, Attraction and Actualize are the major inspirations for innovations based on research of Indian automobile industry. Strategic focus on these inspirations will help to support innovations focus and also increases success potential from innovation. Global automotive industry went through multiple phases since the first vehicle launch. Basic product, mass production of vehicles and lean production are key phases of automotive industry, which were mainly influenced by the demand and supply dynamic of market. Indian automotive industry followed western world to large extent in the past. However, since last decade and half Indian automotive industry went through sea change in-terms of product launches, product development focus and overall customer experience. Market inspirations revealed in this paper will guide innovation and technology managers of automobile industry to align their strategic innovation focus to increase success of products in the market.
\end{abstract}

Keywords: 5 A's, Innovations, Innovation Inspirations, Sources of innovation

\section{Introduction}

Indian automobile industry is one of the largest industry in the world and continuously growing. Indian automobile industry followed western trends and technologies in the initial phase and carried that influence. However, in recent period it is observed that Indian automobile industry and market able to generate its own uniqueness. New product launches in the Indian market in recent time are more aligned with Indian customer's requirements than launching or configuring products available in western markets. Significant efforts puts by home grown automakers and MNCs to innovate there products which meets Indian customer requirements. However, in coming time automakers required to do more than current level of effort and innovate more to be successful in Indian automobile market. Present research is the study of Indian automobile market sales trends and inspirations which can be drawn for Innovations.

The First Car: In 1886, Carl Benz is awarded German patent number 37435 for the three wheeled, selfpropelled "Motorwagen". With a rear mounted single cylinder engine, the first automobile forever changes the way people move and sparks a legacy of innovations that continues to this day. ${ }^{[1]}$ The blueprint of the modern automobile was perfected in Germany and France in the late 1800s; however, North Americans dominated the industry in the first half of the twentieth century. Since Henry Ford innovated mass-production techniques for automobile which sets standard for modern automobile production. Ford, General Motors and Chrysler emerged as the "Big Three" auto companies by the 1920 s in the world ${ }^{[2]}$. Market saturation coincided with technological stagnation: in both product and production technology, innovation was becoming incremental rather than dramatic. Each region in the triad-North America, Europe, and Asia - has made significant contributions to process, product, and organization throughout the twentieth century. These innovations together have shaped the competitive structure of the automotive industry that exists today. ${ }^{[3]}$

The automobile industry has emerged through several stages since its origin like (1) Basic craft / wagon production (1890-1908), (2) mass production vehicle with comfort and safety features (1908-1973), based on Henry Ford's moving assembly lines concept, and (3) lean production (1973-present), which was initiated at Toyota Motors during the 1950s, and which introduced a revolutionary management process of product-development and production. Product innovation in the automobile industry emerged as a response to customer demands, although product positioning is a critical strategic variable for automakers. ${ }^{[4]}$

Global automotive industry changed how human kind move around. "Mobility" without automotive is seems unthinkable and unlikely on this planet in today's world. Automotive world is also changing. Market space is changing and buyers are now looking forward for more plausibility with automotive. ${ }^{[5]}$

In India, first car ran on road is around 1897 and until the 1930s, cars were imported only, and in very few numbers. Indian Automotive industry emerged in 1940 when Hindustan Motors established and introduced "Ambassador" model. Their longtime competitor Walchand group along-with FIAT launched their first Premier model around 1942. Mahindra and Mahindra established in 1945 and started production of Jeep utility vehicle brand. Indian automotive industry evolved through several phases, however, real boost in the industry followed 
after launch of Maruti Suzuki's Maruti 800 car in 1984. Maruti Udyog Limited was joint ventures of Indian Government and Suzuki Motors Japan and they established modern supply chain and new quality standard in Indian Automotive Industry.

Today, automotive industry in India is one of the largest in the world with an annual production of 23.37 million vehicles in FY 2014-15, following a growth of 8.68 per cent over the last year. The automobile industry accounts for 7.1 per cent of the country's gross domestic product (GDP). ${ }^{[6]}$

Automotive industry is transitioned from need to necessity and now transforming towards personification. Innovations and technological advancement boosted the industry transformation.

\section{Literature Review}

Literature review primarily focused on the research related to understanding innovations, importance of innovations in general and in automotive industry context and its inspirations in the automotive world. Literatures related to automobiles and its market impacts also reviewed in Indian automobile industry.

\subsection{Understanding Innovation and its Importance in Automobile industry context}

In today's dynamic and uncertain business world, Innovation is buzz word in the management meetings. Industry experts, thinkers and academicians defined innovations in many different ways; however, most of the definitions are deriving more or less similar meaning ${ }^{[7]}$. Leading strategy consulting firm E\&Y's definition is appropriate summary of innovation definition. "Innovation is the successful development of an idea that generates business value for sustainable growth. Innovation is not a strategy; it's a way of being". ${ }^{[8]}$

As defined by Godin in his work innovation has been broadly conceived and defined as innovation concerns any kind of novelty: artistic, scientific, technological, organizational, cultural, social or individual. ${ }^{[9]}$ At its most powerful, innovation is a driver for rapid and profitable revenue growth. But it can also deliver improved competitive positioning, higher customer satisfaction, and decreased costs. ${ }^{[10]}$

In automobile business context as mentioned in Oliver Wyman (2015) studies "Without innovations as an answer to the key challenges of global megatrends, the entire concept of individual mobility stands at risk." [11]. In today's automotive market, the top twenty OEMs account for $94 \%$ of car production volume and the top five accounts for $52 \%$ of volume. ${ }^{[12]}$ Booz and Co study of automotive market and prediction till 2020, revealed that "The global automotive game will be pretty much decided by twin forces for China and India". [13] McKinsey and Co's prediction is similar, they predicts that automotive industry's economic center of gravity will continue to shift, as sales volumes and market share keep moving towards emerging markets. ${ }^{[14]}$

According to a report published by the Center of Automotive Research the automotive industry spends $\$ 100 \mathrm{~B} /$ year on R\&D, which equates to $\$ 1,200$ per vehicle produced ${ }^{[15]}$ Booz \& Company Perspective provides an analysis of growth prospects in the Indian automotive industry. The main factors behind such growth are the increasing affluence of the average consumer, overall GDP growth, the arrival of ultra-low-cost cars, and the increasing maturity of Indian original equipment manufacturers (OEMs). ${ }^{[16]}$

\subsection{Sources of Innovations and Inspirations}

Great management thinker and guru Dr. Peter Drucker's famous book "7 sources of innovations" is nicely summarized by Penniman Myles mentioned that innovations happens with seven sources i.e. the unexpected (surprise), incongruities (thinking differently), Process need (problem solving approach), changes in the industry and market structure, demographics (change in population), change in perception, and new knowledge. ${ }^{[17]}$

Research report of Ebersberger et.al mentioned that the origins of innovation are different according to the type of innovation identified in research taxonomy (simple/incremental; simple/radical; complex/simple; or complex/radical) ${ }^{[18]}$. Imitation $\rightarrow$ Invention $\rightarrow$ Innovations is the formula mentioned by Godin Benoit in his work Innovation: the history of categorization. ${ }^{[19]}$ There are multiple researcher mentioned innovation sources in multiple ways which are more contextual and duration specific. Hipel's study in his famous book "Sources of Innovations" pointed out that in some fields, innovation users develop most innovations. In others, suppliers of innovation-related components and materials are the typical sources of innovation. ${ }^{[20]}$ Knowledge, Creative thinking and Motivation are the sources of innovation for individual. ${ }^{[21]}$

Mechanization and automation driven major innovations in manufacturing technology of automotive and remained major source innovation in initial period of industry like Ford's moving assembly line, Toyota's Lean manufacturing. Lower price and faster production was key drivers to all the work in early period. Product oriented innovation in the automotive industry has primarily response to customer demands, although product positioning in the market is a critical strategic ingredient for automakers. In context with the introduction of mass production methods introduced need for the vertical organization of production processes. Supply chain management, competitive structure management, decentralization, globalization, legal requirements and overall 
labor cost management was response to increased competition in the market and earnest desire of organizations to be relevant in the competitive market. ${ }^{[22]}$

Automotive organizations are spending enormous amounts on research related to technologies and new products which are fulfilling customer demand and aligned to changing customer expectations. Larger scale studies and market research reports are available on the subject of market requirements and future areas on focus. However, it is becoming imperative to clearly understand what is inspiring automotive industries to innovate?

\subsection{Indian Automotive Industry Perspective}

Mahindra and Mahindra, Tata Motors Limited, Bajaj Auto Ltd., Hero Moto Corp., Force Motors Ltd, TVS Motors, Asia Motor Work, Ashok Leyland are few major key players of Indian automotive industry which are largely managed under the leadership and vision of their own promoters. "The small wonder" a book on making of Tata nano product mentioned that Tata Motors visionary leader Ratan Tata set direction for company's affordable car project as his dream to fulfill his promise during one of his interview. ${ }^{[23]}$. Anand Mahindra then managing director of Mahindra directed his organization to have in-house developed technology for SUV and set-up a IDAM team of highly motivated young engineer for the task in 1998. As mentioned in his speech in SIAM meet 2016, Bajaj Auto's Managing Director Rajeev Bajaj declared to have full technology focus on motor bikes and discontinued business of proven scooter products. These examples are evidences of how the Indian automotive industry is influenced by decision the leaders than the conventional market inspirations. In Indian automotive market major sources of innovations are the direction set by the promoters. However, closer study of thinking of leaders and its impact on the Indian automotive industry direct toward inspirations of innovation.

As mentioned by Porus Munshi in his book making breakthrough innovation happen, Indian ways of innovations are different and might not be following western concepts and researches. ${ }^{[24]}$ Indian innovations popularly known as "jugaad" are inspired in unsystematic ways. ${ }^{[25]}$

\subsection{Identified Gaps in current Research}

Literature review reveals that considerable research work is being carried out to understand the generic sources of innovation and its importance. Literature study also observed that research is also carried out about inspirations of automotive industry innovations and evolutions of automotive industry in the world. [26] However, Indian automotive industry innovation inspirations and sources of innovations are not so evident in current literature and data review and identified as a gap for current research work.

The research work presented in this paper is largely focused on Indian Automobile Industry and its market inspirations for innovations which observed to have some unique dimensions.

\section{Research Methodology}

The present research work is based on following research steps,

\subsection{Data collection from secondary sources}

3.2 Society of Automotive Manufacturers Association (SIAM)

3.3 Leading web portals like Autoportal, IBEF, Wikipedia etc.

3.4 Data is analyzed for trend and key co-relations

Collected data is arranged and refined to some extent i.e. used only key influencing players data, small market share or small sales volume data is not considered in present study.

\subsection{Inferences are drawn from the data to conclude the present work}

The presented data is not analyze using any statistical tool in order to keep the relevance of industry data intact and inference drawn from absolute data.

\section{Research Findings And Discussions}

Five market inspirations which can be drawn from Indian automobile industry for innovations based on this research are as follows,
1.1. Affordability
1.2. Accessibility
(Price, fit to use)
1.3. Addressing
(Availability)
1.4. Attractions
(Problem, Pointing solution)
1.5. Actualize
(Differentiation)
(Customization or individualized based solution)

Discussion of each inspiration is followed next. 
Affordability (Price, Fit for use)

"Affordability" is defined as the correct balance of fuel efficiency, reliability and resale value of the vehicle bundled with lower initial price of vehicle which is fit for use to the end customer.

Indian Automobile Industry observed CAGR increase of $9.4 \%$ over FY-06 to FY 16, during this period passenger vehicle segment grown fastest to CAGR $10.09 \%$ and followed by $2 \mathrm{~W}$ segment which witnessed growth of $9.48 \%$ during the same period ${ }^{[27]}$. However, 2 wheeler segments is predominantly leading the automobile sector sales and considered backbone of Indian personal transportation.

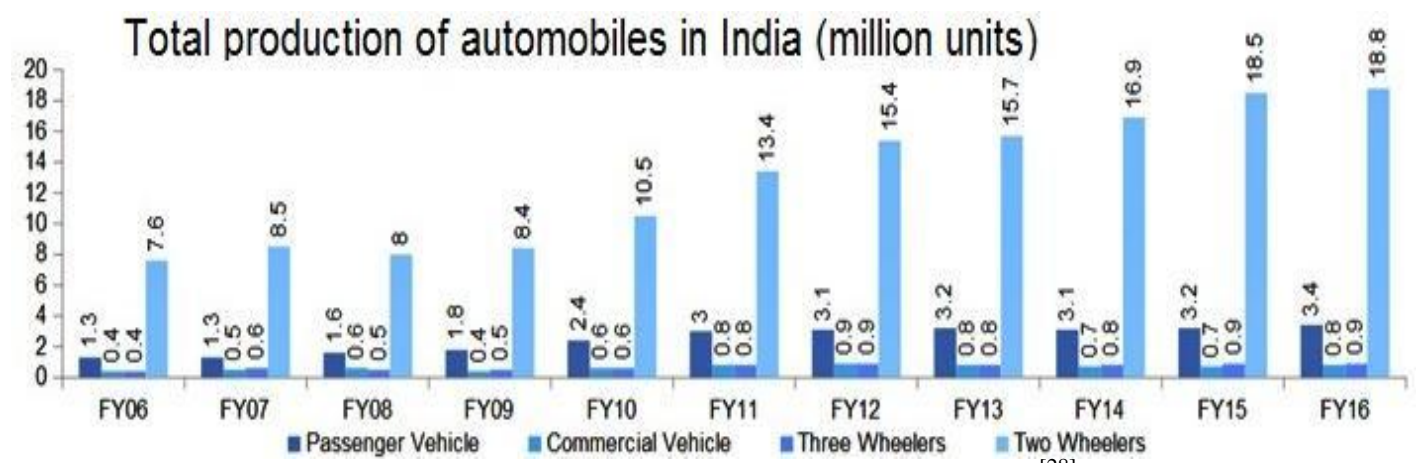

Fig. 1: Total Production of Automobiles in India ${ }^{[28]}$

A cross sectional study of passenger vehicle segment suggest that larger share of passenger car segment sales is attributed to small (segment A) cars and followed by Medium (Segment B) cars. Mid-segment sedan having advantages of fuel economy, lower initial cost and potentially a long distance car is preferred choice of customers in the market. Indian Automobile buyers are obsessed with "value for money" purchase over the other aspects of vehicle.

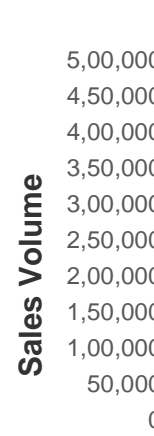

Micro and Segment A Car Sales

2012-13 2013-14 2014-15 2015-16

Nano

$$
\begin{aligned}
& \text { Santro, Eon M800, A-Star, Alto, } \\
& \text { Wagon } \mathrm{R}
\end{aligned}
$$

Kwid

\section{Vehicle Model}

Fig. 2: Micro and Segment A Car Sales in India ${ }^{[29]}$

Maruti Suzuki India Ltd (MSIL) has earned its place in customer's mind as most affordable small car in the market. MSIL is undisputed leader in the Indian automobile market and continuing increase in sales. Interestingly, new launched Renault Kwid got good response from market and will have good growth in coming time. Hyundai Santro and Eon steady and maintaining its place in the market. Surprisingly, TATA nano a mini segment car which launched as alternative to scooter and positioned as most affordable car, could not live to its positioning in the market. It is clear from nano's sales trend, in Indian market customers are not only looking for affordable (price) car but customer respond positively only if the product is fulfilling all the dimensions of affordability. 


\section{Month Top Selling Seg A / B Pass Cars}

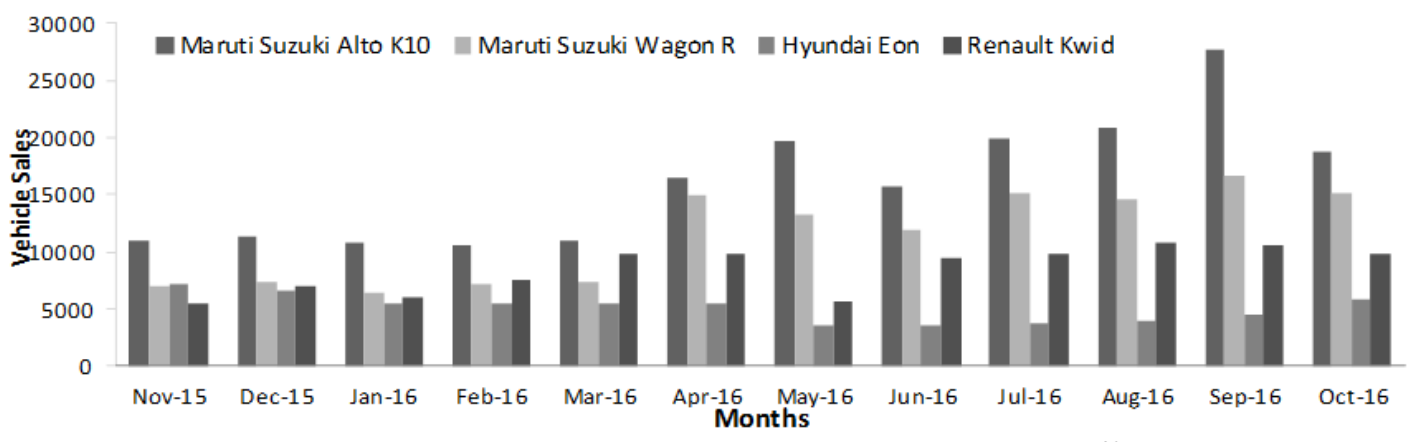

Fig. 3: Last 12 Months Top Selling Segment A / B Cars ${ }^{[30]}$

Two wheelers i.e. motor cycles and scooters are having major share of total automotive market production and sales. In addition to convenience, 2 Wheeler is preferred and affordable mode of personal transportation. Indian two wheeler market is one of the largest in the world because of affordability. Most popular motor cycle models in India are the most fuel efficient, lesser maintenance and lower initial price point vehicles compare to developed countries two wheeler products. Motor cycles in India are more of necessity to buyer than luxury, so affordability is most important factor during the purchase decision.

The common factor of segment A cars are they are having lower initial cost, gives very good fuel efficiency and also they are rugged to carry small family. Segment leader vehicle Alto from Maruti Suzuki is popular and going well in the market because of these dimensions. "Value for Money" is the voice of customer in Indian auto industry and which is the source of first market inspiration of innovation. Indian buyers are choosy when it comes to vehicle purchase. The vehicle purchase decision making is commonly attributed to "kitna deti hai" (what is the fuel economy?), kit ne mai hai? (What is the price?), chalti kaisi hai (how's reliability of vehicle?) and kitna milega (what is resale value?). These are commonly discussed points over the vehicle sales decision which we called as "Affordability"

Affordability is the clear innovation inspiration from the market to automobile industry or automobile organization. Innovations based on affordability principle must be focused on fuel efficiency, reliability and resale value of the vehicle bundled with lower initial price of the vehicle. Renault a French Automaker and one of the late entrant automotive companies to Indian automotive market failed to realize the market dynamics with in initial models. However, the grand success of "Renault Duster" which was built on the affordability principle gave them excellent market entry. Renault's Kwid is the perfect combination of all the principles of affordability i.e. it is having right price, balanced fuel economy, reliable and rugged styling combination made this car popular into Indian market.

Year 2009 Tata Motors launched its "nano" a small car on the principle of affordability to fulfill dream of its visionary chairman Mr. Ratan Tata. The vehicle is capable of carrying small family, safe and initial cost of the vehicle targeted slightly over the motor cycle. Tata nano is very well innovated, engineered and correctly balanced affordability principle product. The vehicle received overwhelming response initially. The vehicle branding "cheapest car in the world" hit the purchaser's aspirations. Even though the nano is having correct balance of affordability principle, it is not able to continue its initial success because of its branding lowered the self-esteem of vehicle owner.

"Affordability" is clear market inspiration for innovation to automakers. Maruti-Suzuki is continuing there market leadership position, fundamentally sticking to this principle and it is clearly re-iterated by success of Renault "Kwid".

\section{Accessibility (Availability)}

"Accessibility" is defined as the total customer experience for the purchase of vehicle including sales, service and availability of automakers resources to make vehicle usage optimally.

Past two decades and half, Maruti Suzuki is leading and dominating the Indian automotive market. One of the major reasons for MSIL's success is its strong and wide dealer, service and sales point network. MSIL is popular in India because of its easy access and satisfying customer services experience across the network. Hyundai motors is enjoying second position in overall market share, however, there is huge difference between MSIL and Hyundai's market share and also the network. Tata Motors is having third largest network in India.

It is important to have good sales points; however, customers are looking beyond sales and service networks. In addition to service network, it is very important for Indian auto customer to have access to company's resources or its add-on network services like vehicle finance, vehicle insurance, easily available 
spares and coverage of road-side assistance in case of vehicle breakdown. Customers expect their vehicle to run without any troubles and in case of troubles vehicle should be made operable in shortest possible time.

As mentioned by C.K. Prahalad "the fortune lies at the bottom of pyramid" and entrepreneurs need to make effort to find the ways to explore the fortunes for business success. ${ }^{[31]}$ Similarly, automobile companies should explore the fortune in the bottom of pyramid. Accessibility principle suggests that customer must have easy access to automakers resources and ecosystem need to be developed to increase access to potential buyers. Indian automobile industry needs increased access to rural customers and improve the customer overall purchase experience to penetrate in the market. Innovative vehicle financing ways needs to be looked for, in order to engage customers and convert the potential buyers into purchaser.

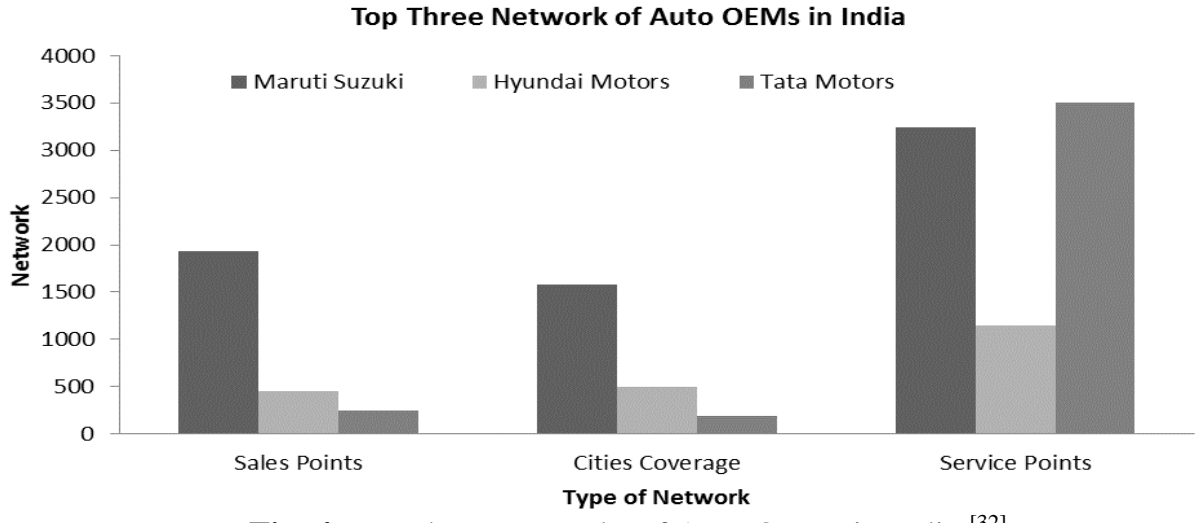

Fig. 4: Top three Networks of Auto OEMs in India ${ }^{[32]}$

Automakers can innovate new business model or new ways of serving customers and increase product accessibility to customers. Mercedes Benz a premier car maker introduced car finance scheme in India to increase their sales. Chevrolet introduce three years no maintenance cost programs or Ford's new estimate service cost upfront and pay only that cost programs are good example of accessibility as well enhanced customer experience.

"Accessibility" is market inspiration for automobile industry for the innovation. In addition to product, process innovations organization must look for innovating there overall customer experience which includes consistent market communication, aligned brand image, delighting after sales service to customer and customer engagement.

\section{Addressing (Problem, Pointing solution)}

"Addressing" is defined as the ability of product / service to solve the problem of customers to largest possible extent or offering best alternative to customers to resolve their problem.

India as a country is experiencing large scale transformation. Since liberalization, country is going through rapid urbanization. Growing middle class population, changing demo-graphics are influencing the tradition and culture of the country. Female working population rapidly increased in the recent times. The pace of urbanization and conversion of cities towards the megacities and metro cities is higher than infrastructure development of the cities. The pace of urbanization added issues like traffic congestion, more time on the road and flexibility i.e. need of personal transportation over inefficient public transport. Individual mobility and its requirements of safe, comfortable and efficient transportation is the key challenges to automobile sector. Market inspiration for innovation can be drawn to solve these issues.

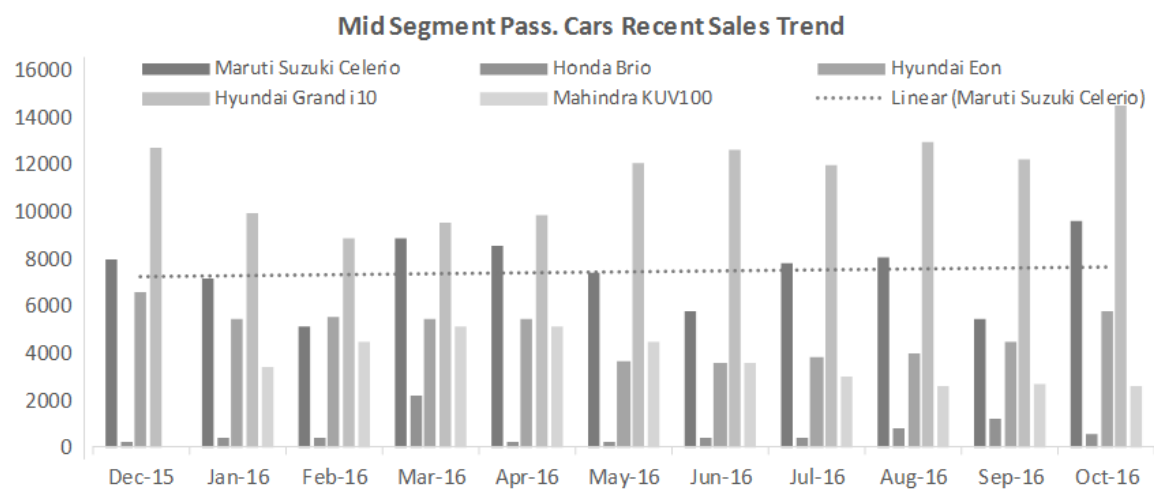

Fig. 5: Mid Segment Pass Cars sales trend in India ${ }^{[33]}$ 
India's leading automobile company MSIL launched its first and India's first AMT vehicle the Celerio which is positioned as a city car around 2014. It is marketed to compete with the Tata Indica Vista, Honda Brio, Hyundai i10, Ford Figo, Chevrolet Beat, and Nissan Micra Active. (www.wikipedia.org). this car was launched keeping increasing female drivers populations in mind. The car become immediately popular in the market as it gave freedom from frequent gear changes and clutch operation to drivers which is adding comfort to drivers and right solution to congested traffic driving. Maruti Suzuki announced in Sept 2016 that the sale of Auto Gear Shift vehicles from its repertoire has crossed the 50,000 units mark. (www.indianautoblog.com) ${ }^{[34]}$

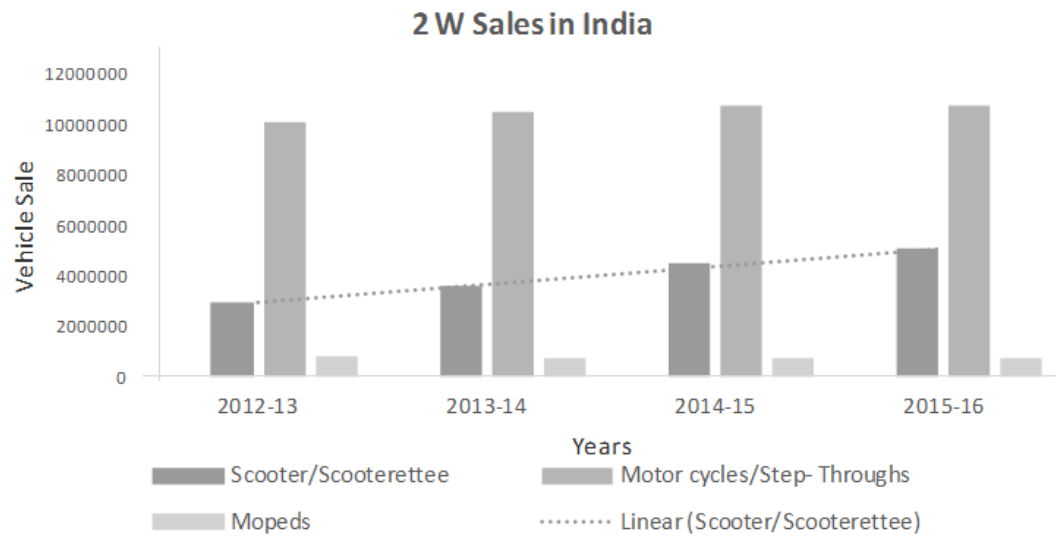

Fig. 6: 2 Wheeler Sales in India ${ }^{[35]}$

After launch of MSIL's Celerio, most of the industry players launched or preparing to launch automated or automatic powertrain vehicles in the market.

Industry experts were of the opinion that era of scooters is over in India. Industry leading vehicle manufacturer Bajaj Auto Ltd., went to extent that they discontinued production of their flagship scooter products in India and focused on motor cycles in response to changing market dynamics.

However, urbanization and need of affordable personal transportation re-created space for automated scooters. Traffic congestions, increased female mobility and cramped parking space in city areas pushed need for scooter sale. Honda Activa a modern gearless scooter is launched keeping unisex riders in mind. Since launch of this vehicle Honda is enjoying marker leader position capturing half of the total scooter market share in Indian market. Motorcycle sales is growing at slower pace than the scooter mainly because of scooters multiutility and comfort ride advantage.

Celerio and Honda Activa's success clearly leading that "Addressing" customer problem or providing solution to pressing social issue is the market inspiration for innovation. Many innovations will take inspiration from Indian market "Addressing” pressing issue of customer.

\section{Attractions (Differentiation)}

"Attraction" is defined as the ability of product to provide exclusivity to the owner of the vehicle by virtue of its look, feel or perceptions.

Historically, Indian society loves to be different. Indian society is based social classes like income and income sources. Each region is having different ways of presenting their social status. Close observation of society reveals the influence of this thinking in the vehicle purchase pattern.

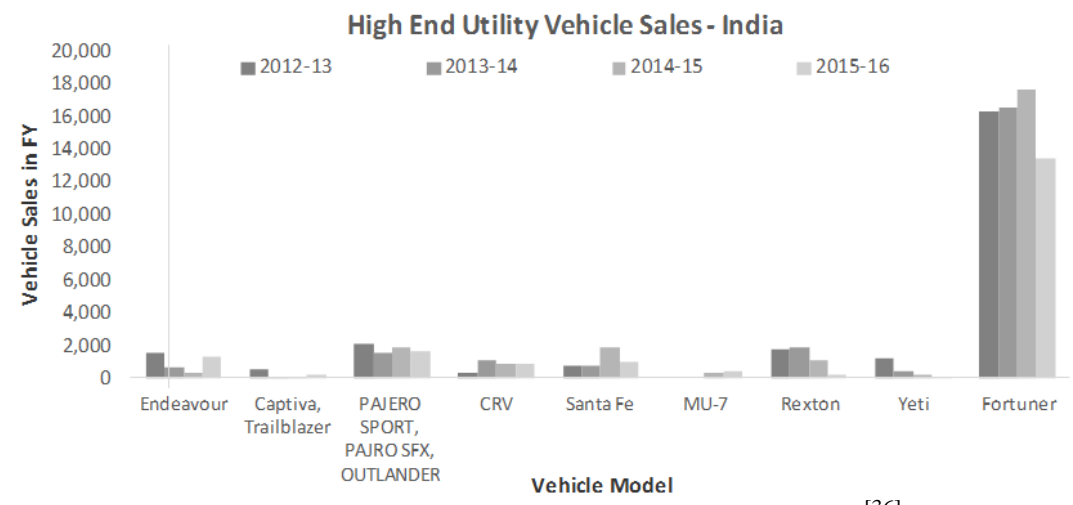

Fig. 7: High End Utility Vehicle Sales in India ${ }^{[36]}$ 
Toyota Fortuner perceived as high class society people vehicle. Toyota Fortuner vehicle is purchased by customer who are into professions like business owners, political leaders etc. Toyota Fortuner made its place since its launch into Indian market and mainly popular in the sectors of buyer. This vehicle does not score very high on technological superiority compare to other vehicles in this class, however, its perception created firm place in customers mind. Pajero, Outlander are also popular with celebrity customers. Mahindra launched its XUV 500 and Scorpio vehicle to address this sector buyers addressing "affordable" alternative to this high end utility vehicles.

Indian Automobile market provides clear inspiration for customer experience innovation and creation of brand image to position the product. "Perceived" customer and societal value driven innovation is needed to address this sectorial customers which is the principle of Attraction.

\section{Actualize (customization or individualized based solution)}

"Actualize" is defined as the customization of products which is not possible with mass production or standard production environment suitable for individual's problem or specific needs.

Indian market is hugely diverse geographically as well as culturally, which cannot be addressed with mass produced standard products even with multiple special models. Indian customers are looking for customized products based on their specific needs, specific usage not necessarily driven by only differentiation. It is observed during the research that lots of activities are happening in the market, however, seems that this sector is combination of organized and un-organized players. It is difficult to estimate exact size of this market, however, roughly it can be estimated that un-organized sector size is same or little more than organized sector. Individual based solutions are driven from specific utilities like farmers who are using $2 \mathrm{~W}$ always look for carrier suitable to be fitted on his motorcycle so that he can carry good like milk containers, daily use farm produce etc. Small moving retailers requires way of loading daily sales items on vehicles. Local areas specific styling of vehicles, socially accepted messages stickers are part of customization of vehicles. This type of solutions are coming from local fabricators and they are highly individualized solutions. Definitely, these are innovative solutions and available at highly reasonable price. These inspirations are very area specific and address regionally / locally itself. However, some key industrials belts like Ludhiana, earned names in this specific customized solutions.

Customization of cars is organized business and considered to be upscale business. Names like Dilip Chabira promoted firms DC design are popular car customizers. However, there are many unorganized business houses smaller in size but providing specific solutions like building designer load carriers, cabins on commercial vehicle chassis. Bus body building is commonly observed customization. These solutions driven from attending specific need of customers (custom solution) but do not govern by any regulations at this point.

There many examples of innovations which inspired auto OEMs to consider and also adopt for mass produced vehicles. Some OEMs are considering these solutions as optional offerings along-with standard products like roof top mounted carriers for cars.

"Actualize" is market inspiration for innovations and provides not only inspiration for innovation also challenges the industry to provide suitable solutions to attract customers.

\section{Conclusion}

Indian automotive industry covers diverse market space influenced by several factors like culture, geographical preferences and social belief. It can be clearly observed influence of these factors from sales data of automotive industry particularly passenger cars and personal transport vehicles like $2 \mathrm{Ws}$. The present research is study of Indian automobile industry's change triggers and inspirations can be drawn from market for innovations. Research revealed that there are five major inspirations which can be drawn for innovation from Indian automobile industry. This research termed these five main inspirations as five A's of market inspiration for innovations. Affordability (Price, fit to use), Accessibility (Availability), Addressing (Problem, Pointing solution), Attractions (Differentiation, availability of solutions to wants than need), Actualize (customization or individualized based solution). Market inspirations revealed in this paper will guide innovation and technology managers of automobile industry to align their strategic innovation focus to increase success of products in the market. Automotive OEMs and other players use these inspiration to strategies and focus their innovation initiatives to be successful in the Indian automotive market.

\section{Acknowledgements}

Authors express their sincere gratitude NEI team members for their contribution to data for this research. 


\section{References}

[1]. Mercedes Benz Website www.mbusa.com. Retrieved from https://www.mbusa.com/mercedes/benz/innovation

[2]. Website of History www.histroy.com Retrieved from http://www.history.com/topics/automobiles

[3]. Gale, Thomson, Automobile history. International Encyclopedia of the Social Sciences, 2008. Retrieved from: http://www.encyclopedia.com/social-sciences-and-law/economics-business-and-labor/businesses-and-occupations/automobileindustry

[4]. Website of Encyclopedia www.encyclopedia.com

[5]. Oliver Wyman, A comprehensive study on innovation in the automotive industry, 2015 Car Innovation. Oliver Wyman, 2015.

[6]. Retrieved from: http://www.oliverwyman.com/content/dam/oliver-wyman/global/en/2014/dec/CarInnovation2015_eng_final.pdf

[7]. Website of Wikipedia, www.wikipedia.org. Retrieved from https://en.wikipedia.org/wiki/Automotive_industry_in_India

[8]. Dabholkar, Vinay \& Krihanan, Rishikesha T., 8 Steps to innovations: going from jugaad to excellence. India (Collins Business India, 2013).

[9]. Dewar, Robert D., Dutton Jane E., The adoption of radical and incremental innovations: an empirical analysis, Management Science. 32 (11), 1986.

[10]. Keeley Larry, Pikkel Ryan, Quinn Ryan, Walters Helan. Ten types of innovations [brochure, 2015]. USA. Retrieved from http://www.doblin.com/tentypes

[11]. Ernst \& Young, Innovating for growth: Innovation 2.0 - a spiral approach to business model innovation, E\&Y, 2012. Retrieved from: www.ey.com/growingbeyond

[12]. Godin Benoit, Innovation: the history of category, Project on the Intellectual History of Innovation. The working paper No.1, 2008.

[13]. PWC, Breakthrough innovation and growth: top innovators expect usd 250 billion five year revenue boost, Pricewater Cooper, 2013. Retrieved from: https://www.pwc.com/ca/en/consulting/publications/pwc-breakthrough-innovation-growth-canada-2013-11en.pdf

[14]. Kalmbach Ralf, Bernhart Wolfgang, Kleimann Philipp Grosse, Hoffmann Marcus, Automotive landscape 2025: opportunities and challenges ahead, RolandBerger Strategy Consultant, Auto Industry Study Report, 2011. Retrieved from: http://www.forumelektromobilitaet.ch/fileadmin/DATA_Forum/Publikationen/Roland_Berger_2011_Automotive_Landscape_2025_E_20110 228.pdf

[15]. Booz\&Co, India automotive market 2020, [PowerPoint slides] (Booz \& Co, 2011). Retrieved from: www.strategyand.pwc.com/media/.../Strategyand-India-Automotive-Market-2020.pdf

[16]. McKinsey, The road to 2020 and beyond: what's driving the global automotive industry?. McKinsey \& Co, 2013. Retrieved from: www.mckinsey.com/.../Automotive\%20and\%20Assembly/.../McK_The_road_to_2025 and beyond: what's driving the global automotive industry?,pdf. Center for Automotive Research Report 2015

[17]. Sehgal Vikas, Ericksen Mathew, Sachan Sunil, Reviving the growth engine: India's Automotive Industry is on a fasttrack. Booz \&

[18]. Co., 2009 Retrieved from: www.strategyand.pwc.com/media/file/Revving_the_Growth_Engine.pdf

[19]. Penniman. Myles, 7 Sources of Innovations. [Book Summary, 2012] Retrieved from: http://mylesclarku.blogspot.in

[20]. Ebersberger Bernd, Laursen Keld, Saarinen Jani, Salter Ammon, The origins of innovation: an analysis of the finnish innovation

[21]. database, Paper to be presented at the 4th European Meeting on Applied Evolutionary Economics (EMAEE): Geography, Networks and Innovation, Marinus Ruppert building, Utrecht University, De Uithof, Utrecht, The Netherlands, 19-21 May 2005.

[22]. Hippel Eric von, The sources of innovations (Oxford University Press, New York, USA, 1988).

[23]. Karlyn Adams, The sources of innovations and creativity (National Center on Education and the Economy (NCEE), EU, 2005).

[24]. Brödner Peter, Latniak Erich, Sources of innovation and competitiveness: national programs supporting the development of work organization. Report to DG Employment and Social Affairs. Institute for Work and Technology, 2002.

[25]. Yogi, Vikas, Automobile history - top 10 interesting facts. 2014 Retrieved from: http://auto.ndtv.com/news/automobile-history-top10-interesting-facts-390242

[26]. Chacko Philip, Noronha Chritabelle, Agarwal Sujatha, Small Wonder the making of the nano. (Westland Ltd. India, 2010).

[27]. Munshi Porus, Making the break through innovation happen. (Collins Business in association with The India Today Group, India, 2009)

[28]. Radjou Navi, Prabhu Jaideep, Ahuja Simone, Jugaad innovation (Random House India. First published by Jossey-Bass, A Wiley

[29]. Imprint, CA, USA, 2012).

[30]. IBEF Website, www.ibef.org Retrieved from: http://www.ibef.org/industry/automobiles-presentation

[31]. Society of Indian Automotive Manufacturers website, www.siam.org,

[32]. Auto Portal Website, www.autoportal.com Retrieved from https://en.wikipedia.org/wiki/Suzuki_Celerio

[33]. Prahalad C.K., The fortune at the bottom of pyramid (Dorling Kindersley India Pvt. Ltd., India, 2011).

[34]. Website of Wikipedia, www.wikipedia.org

[35]. Website of Maruti Suzuki India Ltd., www.marutisuzuki.com

[36]. Website of Indian Auto Blog., www.indianautoblog.com, Retrieved from: http://indianautosblog.com/2015/09/maruti-amt-cars50000- mark-195703 